\title{
Optimization of Electrical and Magnetic Behaviour of Nanosized $\mathrm{Mn}_{0.45} \mathrm{Ce}_{\mathrm{x}} \mathrm{Fe}_{2.55-\mathrm{x}} \mathrm{O}_{4}$
}

\author{
Samiha T. Bishay \\ Department of Physics, Faculty of Girls for Science Art and Education, \\ Ain Shams University, Cairo, Egypt
}

Nano-particles polycrystalline $\mathrm{Mn}_{0.45} \mathrm{Ce}_{x} \mathrm{Fe}_{2.55-\mathrm{x}} \mathrm{O}_{4} ; \mathrm{x}=0.0$ and 0.1 were synthesized using the co-precipitation method and subsequently heat-treated. In each heat treatment the prepared samples have been investigated by XRD and TEM. The electric and magnetic properties for each heat treatment have been studied to produce samples with distinguishable character that can be suitably used in different technological applications. The obtained hysteresis loop of all the investigated samples belong to the Isoperm loop. The $\mathrm{Mn}_{0.45} \mathrm{Ce}_{0.1} \mathrm{Fe}_{2.45} \mathrm{O}_{4}$ samples with particle size $(9.9 \mathrm{~nm})$ are characterized by the lowest coercive field (28.87Oe) and highest $T_{C}(582 \mathrm{~K})$, they can be used in medical applications. The samples $\mathrm{Mn}_{0.45} \mathrm{Fe}_{2.55} \mathrm{O}_{4}(45 \mathrm{~nm})$ after two steps of heating treatment shows a paramagnetic behavior and have the highest remenance ratio (0.236) and a very low dielectric loss (0.07). They can thus be used as memory storage and in several microwave applications. $\mathrm{Mn}_{0.45} \mathrm{Fe}_{2.55} \mathrm{O}_{4}(50 \mathrm{~nm})$ after three steps of heating treatment has the highest dielectric constant (1500), the lowest resistivity and lowest activation energy $(0.38 \mathrm{eV})$, which are the suitable properties needed for the electronic devices.

\section{Introduction:}

In recent decades, nanometric scale particles have attracted great interest in fundamental science and also in technological applications. In Fact, nanoparticles have created a new type of materials, which possess some novel and enhanced physical and chemical properties $[1,2]$. Spinel ferrites are one of the most significant magnetic materials which have been extensively used in modern electronic technologies [3], such as high density magnetic information storage, magnetic resonance imaging and target drug delivery [4, 5]. Many works were carried out to prepare nanoparticles ferrites. Ahmed et al. [6] studied the characterization and magnetic properties of $\mathrm{MnFe}_{2} \mathrm{O}_{4}$ prepared by five different methods and reported that the smallest nano-particle sizes were obtained by the citrate method $(14.1 \mathrm{~nm})$. Alvani et al. [7] used the ball milling process to prepare $\mathrm{MnFe}_{2} \mathrm{O}_{4}$ with nanocrystals of an average size $5 \mathrm{~nm}$. They 
compared the hydrogen production of the samples prepared by ball mill with that prepared by thermally activated solid-state reaction. Binfag et al. [8] studied the effect of the chemical temperature reaction on the preparation of $\mathrm{MnFe}_{2} \mathrm{O}_{4}$ by co-precipitation method. The nature of the initial co-precipitates, the change of the structure during ageing in the temperature range $25-95^{\circ} \mathrm{C}$ as well as the structure of the resulting ferrite phases have been discussed by Musat Bujoreanu et al. [9].

Dielectric behavior is one of the most significant properties of ferrites, which clearly depends on the preparation conditions, composition and the grain size [10-12]. Moreover, the magnetic properties of ferrites are strongly affected by the grain size. Gillot and Tailhades [13] have investigated the temperature dependence of oxidation behavior and coercivity evaluation of a series of manganese cobalt ferrite. The work of Wang et al. [14] was mainly concerned with measuring the low field magneto resistance of $\mathrm{MnFe}_{2} \mathrm{O}_{4}$ nanoparticles compact. Also, in $[8,15]$ the powder magnetic properties of $\mathrm{MnFe}_{2} \mathrm{O}_{4}$ were characterized with a vibrating sample magnetometer VSM.

The aim of the present work is to prepare of nano size particle ferrites $\mathrm{Mn}_{0.45} \mathrm{Ce}_{\mathrm{x}} \mathrm{Fe}_{2.55-\mathrm{x}} \mathrm{O}_{4}, \mathrm{x}=0.0$ and 0.1 using the co-precipitating method with different heat treatments. The main achievement is the production of novel samples that are characterized by significant properties needed in many applications in the field of nano-technology.

\section{2- Experimental Techniques:}

Nano-sized $\mathrm{Mn}_{0.45} \mathrm{Ce}_{\mathrm{x}} \mathrm{Fe}_{2.55-\mathrm{x}} \mathrm{O}_{4}, \mathrm{x}=0.0$ and 0.1 was prepared by the co-precipitation method. Stoichiometric amounts of $\mathrm{Mn}\left(\mathrm{NO}_{3}\right)_{2} \cdot 4 \mathrm{H}_{2} \mathrm{O}$, $\mathrm{Fe}\left(\mathrm{NO}_{3}\right)_{3} \cdot 9 \mathrm{H}_{2} \mathrm{O}$ and $\mathrm{Ce}_{2}\left(\mathrm{SO}_{4}\right)_{3} \cdot 8 \mathrm{H}_{2} \mathrm{O}$ were dissolved in distilled water. Sodium hydroxide solution was slowly added until the solution became neutral. The mixture was left for $24 \mathrm{~h}$ to precipitate and then filtered, washed by distilled water for several times, dried and pressed into pellets. The pellets were classified into three different groups (A, B and C) and subsequent heat treatments were performed as reported in Table (1). Sample D having the composition formula $\mathrm{Mn}_{0.45} \mathrm{Fe}_{2.55} \mathrm{O}_{4}$ was prepared using the stander ceramic technique, which was reported previously, in detail, in our earlier work [16, 17]. The pre-sintering and sintering conditions are clarified in Table (1). All the heat treatments were carried out using a Lenton furnace (England) UAF 1615 with microprocessor to control both heating and cooling rates. 
Table (1): The classification and heat treatments of the investigated samples.

\begin{tabular}{|c|c|c|c|}
\hline Sample & $\begin{array}{l}\text { Composition } \\
\text { (formula) }\end{array}$ & $\begin{array}{l}\text { Preparation } \\
\text { Method }\end{array}$ & Heat treatment \\
\hline A & $\mathrm{Mn}_{0.45} \mathrm{Ce}_{0.1} \mathrm{Fe}_{2.45} \mathrm{O}_{4}$ & Co-precipitation & $\begin{array}{l}\text { Heated at } 500{ }^{\circ} \mathrm{C} \text { for } 4 \mathrm{~h} \text { with } \\
\text { heating/cooling rate } 20{ }^{\circ} \mathrm{C} \cdot \mathrm{min}^{-1}\end{array}$ \\
\hline B & $\mathrm{Mn}_{0.45} \mathrm{Fe}_{2.55} \mathrm{O}_{4}$ & Co-precipitation & $\begin{array}{l}\text { - Heated at } 500{ }^{\circ} \mathrm{C} \text { for } 4 \mathrm{~h} \text { with } \\
\text { heating/cooling rate } 20^{\circ} \mathrm{C} \cdot \mathrm{min}^{-1} \\
\text { - Annealed at } 900{ }^{\circ} \mathrm{C} \text { for } 4 \mathrm{~h} \text { with } \\
\text { heating/cooling rate } 4{ }^{\circ} \mathrm{C} \cdot \mathrm{min}^{-1}\end{array}$ \\
\hline $\mathrm{C}$ & $\mathrm{Mn}_{0.45} \mathrm{Fe}_{2.55} \mathrm{O}_{4}$ & Co-precipitation & $\begin{array}{l}\text { - Heated at } 500{ }^{\circ} \mathrm{C} \text { for } 4 \mathrm{~h} \text { with } \\
\text { heating/cooling rate } 20^{\circ} \mathrm{C} \cdot \mathrm{min}^{-1} \\
\text { - Annealed at } 900{ }^{\circ} \mathrm{C} \text { for } 4 \mathrm{~h} \text { with } \\
\text { heating/cooling rate } 4{ }^{\circ} \mathrm{C} \cdot \mathrm{min}^{-1} \\
\text { - Annealed at } 1200{ }^{\circ} \mathrm{C} \text { for } 10 \mathrm{~h} \text { with } \\
\text { heating/cooling rate } 2^{\circ} \mathrm{C} \cdot \mathrm{min}^{-1}\end{array}$ \\
\hline $\mathrm{D}$ & $\mathrm{Mn}_{0.45} \mathrm{Fe}_{2.55} \mathrm{O}_{4}$ & Ceramic & $\begin{array}{l}\text { - Pre-sintered at } 900{ }^{\circ} \mathrm{C} \text { for } 4 \mathrm{~h} \text { with } \\
\text { heating/cooling rate } 4^{\circ} \mathrm{C} \cdot \mathrm{min}^{-1} \\
\text { - Sintered at } 1200{ }^{\circ} \mathrm{C} \text { for } 10 \mathrm{~h} \text { with } \\
\text { heating/cooling rate } 2^{\circ} \mathrm{C} \cdot \mathrm{min}^{-1}\end{array}$ \\
\hline
\end{tabular}

The structural properties of all samples were investigated at room temperature by X-ray diffraction (XRD) (Proker $\mathrm{D}_{8}$ ) with $\mathrm{Cu}-\mathrm{K} \alpha$ radiation of wavelength $\lambda=1.5481 \AA$. Crystal size values were estimated by using Scherrer's equation. Transmission electron microscope Joel- TEM-1230 was used to investigate the size and the morphology of particles of the prepared samples. It is provided with a computer program that gives directly the particle size. The TEM investigated samples were prepared by addition of ethylene glycol to the dried powder and subsequent dispersion by ultra-sonification for $10 \mathrm{~min}$. One drop of the suspension was put on a conventional carbon-coated copper grid and was dried in normal air to use in the TEM apparatus.

For measuring the dielectric properties of the samples, the two surfaces of each pellet were polished, coated with silver paste and checked for good conductor. RLC bridge (Hioki model 3530 Japan) was used for these measurements in the range of $(300 \mathrm{~K}-650 \mathrm{~K})$ and different frequencies (200 $\mathrm{kHz}-3 \mathrm{MHz}$ ). K-type thermocouple connected to a digital thermometer (USA) with a junction in contact with the sample was used to measure the temperature of the sample with an accuracy $\pm 1{ }^{\circ} \mathrm{C}$. 
The hystersis loop was measured at room temperature by (9600-1 VSM) vibrating sample magnetometer. The magnetic susceptibility was measured using Faraday's method in which a very small quantity of fine powder of the sample was inserted in the non-homogeneous field (at maximum force point). The measurements were performed at different temperatures $(300 \mathrm{~K}-650 \mathrm{~K})$ and different field intensities (6600e-1690 Oe).

\section{Results and discussion:}

\subsection{Crystalline Structure:}

Figure (1) displays the XRD curves for $\mathrm{Mn}_{0.45} \mathrm{Ce}_{\mathrm{x}} \mathrm{Fe}_{2.55-\mathrm{x}} \mathrm{O}_{4} ; \mathrm{x}=0.0$ and 0.1 prepared at the above different conditions (samples A, B, C, D). The results indicate that all the samples are composed of the spinel crystalline phase in addition to secondary phases. Diffraction peaks are located in the position for $\mathrm{MnFe}_{3} \mathrm{O}_{4}$ [74-2403] cubic lattice although several peaks corresponding to $\mathrm{Fe}_{2} \mathrm{O}_{3}$ [77-2234] rhombohedral lattice were also detected. A possible explanation is that, manganese ferrite is unstable when cooling in air, as it starts to decompose according to the following reaction:

$$
2 \mathrm{MnFe}_{2} \mathrm{O}_{4}+1 / 2 \mathrm{O}_{2} \rightarrow \mathrm{Mn}_{2} \mathrm{O}_{3}+2 \mathrm{Fe}_{2} \mathrm{O}_{3}
$$

Therefore, the other phases may be $\alpha-\mathrm{Mn}_{2} \mathrm{O}_{3}$ solid solution or $\alpha-\mathrm{Fe}_{2} \mathrm{O}_{3}$ solid solution due to decomposition that takes place [18-20].

The lattice parameters and the crystal size of $\mathrm{MnFe}_{2} \mathrm{O}_{4}$ are calculated and reported in Table (2). The crystal size (C) as calculated from XRD analysis (Scherrer's equation) agrees within reasonable percentage difference with that deduced from TEM inspection. The theoretical density $\left(D_{x}\right)$ and specific surface area $\mathrm{S}$, which is calculated from the formula $\left(S=6000 / \mathrm{D}_{\mathrm{x}} \mathrm{C}\right)$ [8], are reported in Table (2). The data show that sample A has the lowest crystal size and highest specific surface area.

Table (2): Effect of preparation conditions and Ce-doping on lattice parameter, crystal size, theoretical density $\mathrm{D}_{\mathrm{x}}$ and specific surface area $\mathrm{S}$.

\begin{tabular}{|c||c|c|c|c|c||}
\hline \multirow{2}{*}{ Sample } & \multirow{2}{*}{$\begin{array}{c}\text { Lattice parameter, } \\
\text { a }(\AA)\end{array}$} & \multicolumn{2}{|c|}{$\begin{array}{c}\text { Crystal size } \\
(\mathrm{nm})\end{array}$} & \multirow{2}{*}{$\begin{array}{c}\mathrm{D}_{\mathrm{x}} \\
\left(\mathrm{g} \mathrm{m}^{-3}\right)\end{array}$} & \multirow{2}{\mathrm{S}}{} \\
\cline { 3 - 4 } & & Scherrer & TEM & & \\
\hline \hline $\mathrm{A}$ & 8.4819 & 9.6 & 9.9 & 5.038 & 122.830 \\
\hline $\mathrm{B}$ & 8.5201 & 45.2 & 45.9 & 4.964 & 25.070 \\
\hline $\mathrm{C}$ & 8.5078 & 50.4 & 50.8 & 4.986 & 25.603 \\
\hline $\mathrm{D}$ & 8.4943 & 108.6 & 109.0 & 5.009 & 11.562 \\
\hline
\end{tabular}



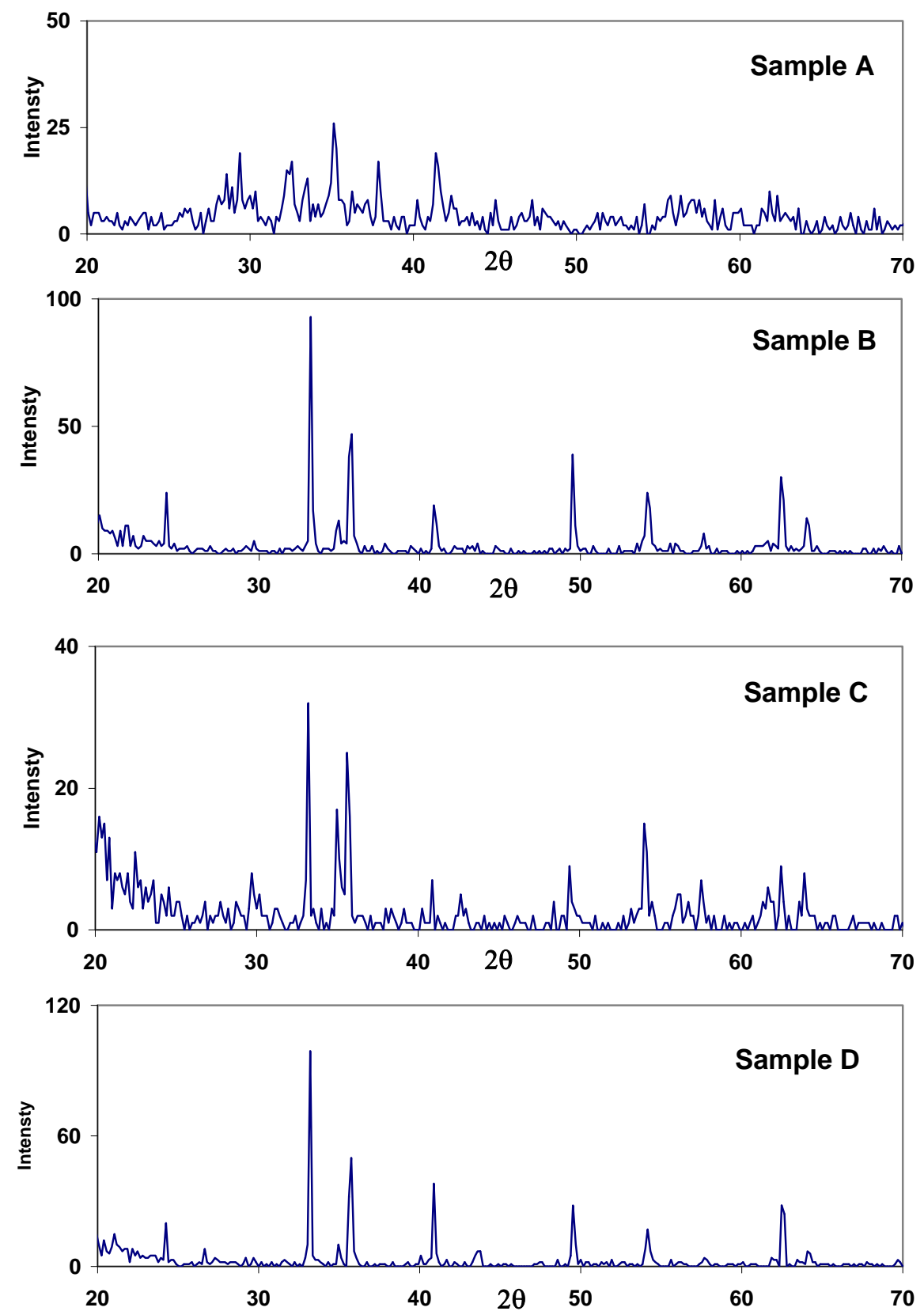

Fig. (1): XRD for the samples A, B, C and D. 
Figure (2) represents the TEM images for all the investigated samples A, $\mathrm{B}, \mathrm{C}$ and $\mathrm{D}$. The TEM image for sample A shows the homogeneous distribution of rare earth cation among the crystals [21]. The particle size is very narrow about $9.9 \mathrm{~nm}$ which agrees with that calculated from XRD $(9.6 \mathrm{~nm})$. The representative TEM images for samples $\mathrm{B}$ and $\mathrm{C}$ illustrate the clear dispersion of nano-particles $\mathrm{MnFe}_{2} \mathrm{O}_{4}$ of average size 45.9 and $50.8 \mathrm{~nm}$ homogeneously through the spherical hematite nano-particles with size about $100 \mathrm{~nm}$. So the magnetism is enhanced in sample C. Fig. (3) shows the selected area electron diffraction SAED for samples A, B, C and D. It is worthwhile pointing out that the SAED of samples A, B and C are dominated by diffraction rings, which is an indication that the nano prepared samples, are in the polycrystalline state. The SAED pattern of sample C, further, exhibits a clear specific orientation of the particles.

Sample A

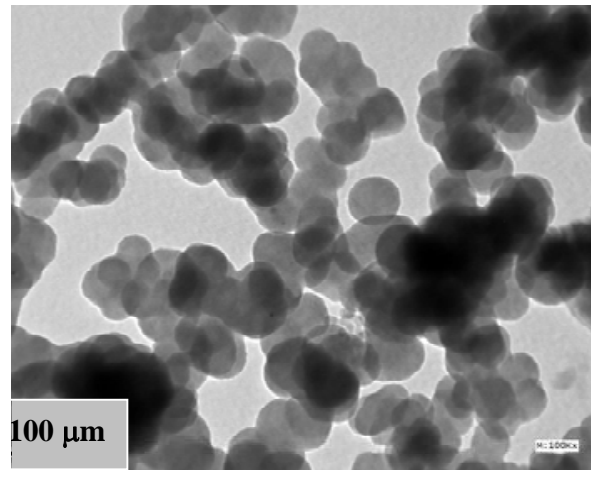

Sample C

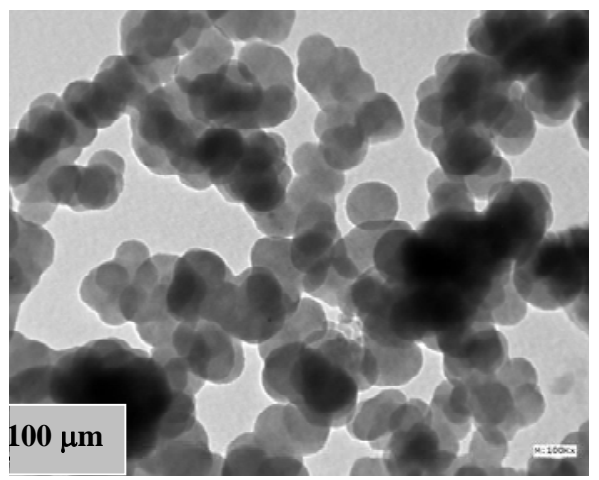

Sample B

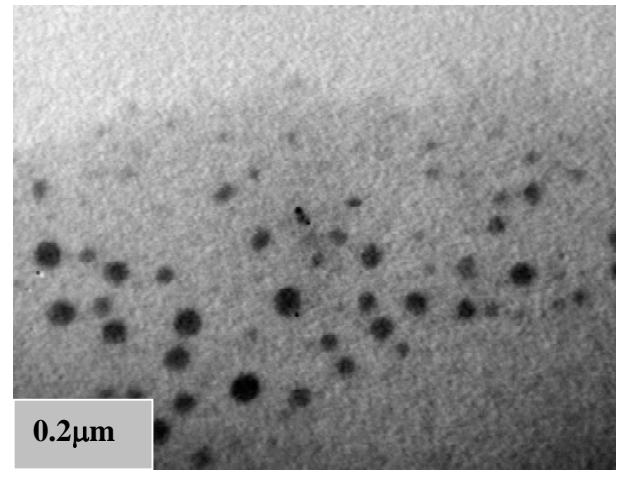

Sample D

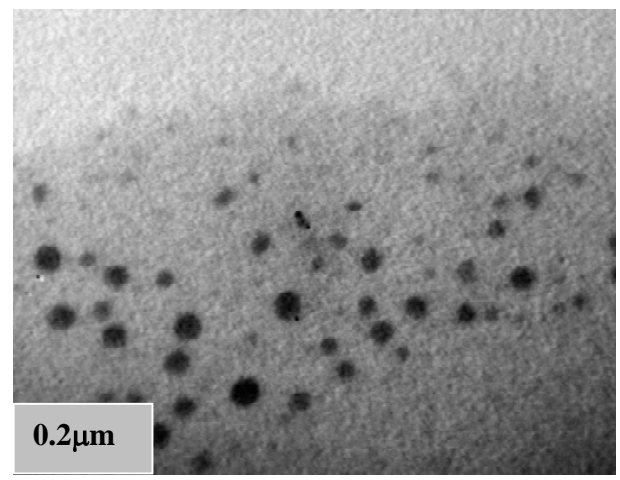

Fig. (2): The transmitted electron microscope TEM for samples A, B, C and D. 
Sample A

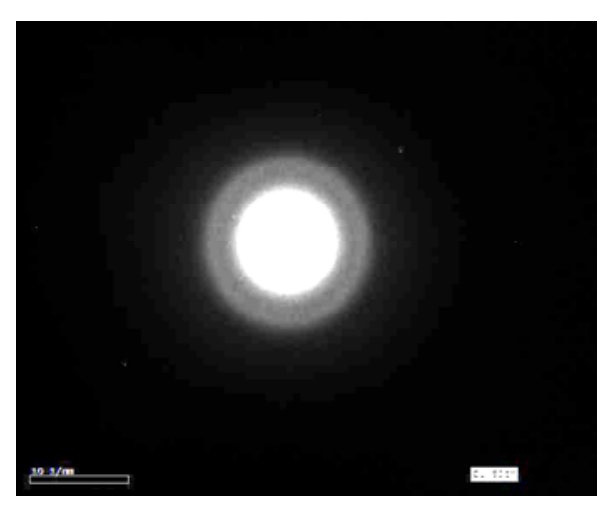

Sample C

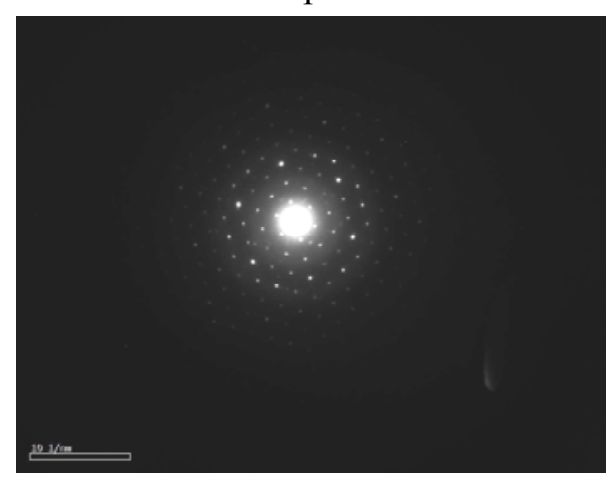

Sample B

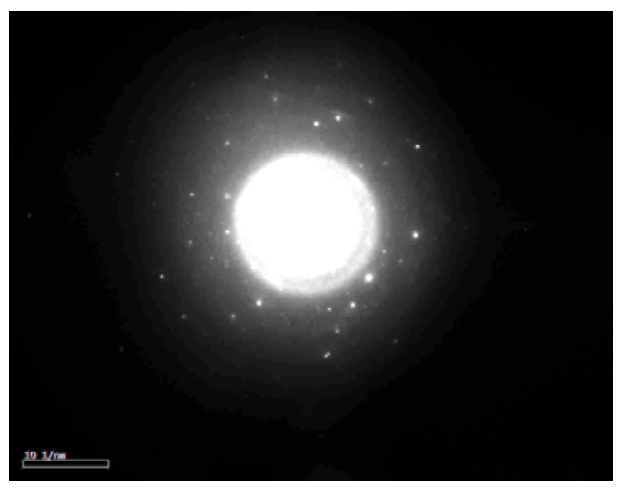

Sample D

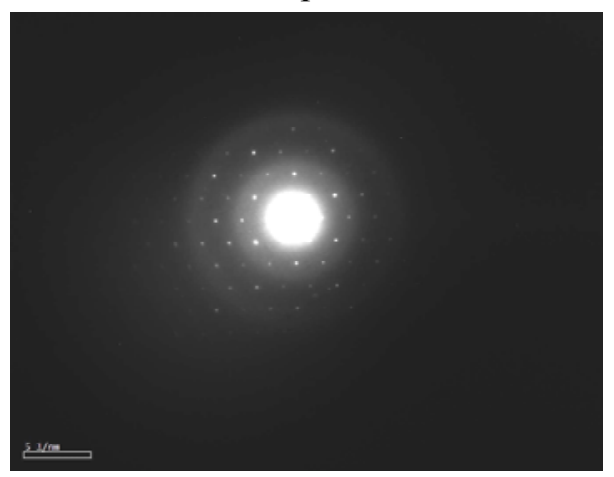

Fig. (3): Selected area electron microscope diffraction pattern for the samples $\mathrm{A}, \mathrm{B}, \mathrm{C}$ and D.

\subsection{Magnetic properties:}

At room temperature the magnetic hysteresis loops of the investigated samples was carried out using 9600-1 VSM vibrating sample magnetometer and are shown in Fig. (4). They all belong to the Isoperm loops, which result in many cases of manganese ferrites [22]. It is known that the ferrites characterize by Isoperm loops are isotropic and have high initial permeability up to $2700 \mu_{\mathrm{o}}$. Furthermore, Isoperm loops in ferrites are formed in a particular temperature range. At higher or lower temperatures they pass over into normal loops or into rectangular loops respectively. The variation of the magnetic parameters as a function of crystal size is illustrated in Table (3). The data show a strong dependence of the magnetic parameters on the preparation heating conditions 
for $\mathrm{Mn}_{0.45} \mathrm{Ce}_{\mathrm{x}} \mathrm{Fe}_{2.55-\mathrm{x}} \mathrm{O}_{4} ;(\mathrm{x}=0.0,0.1)$. It is clear that the two parameters $\mathrm{H}_{\mathrm{C}}$ and $\mathrm{H}_{\text {Max }}$, which determine the ferromagnetic nature of the samples increase with the crystal size because the anisotropic energy barrier for rotation of magnetic moments is proportional to the particle volume [23].
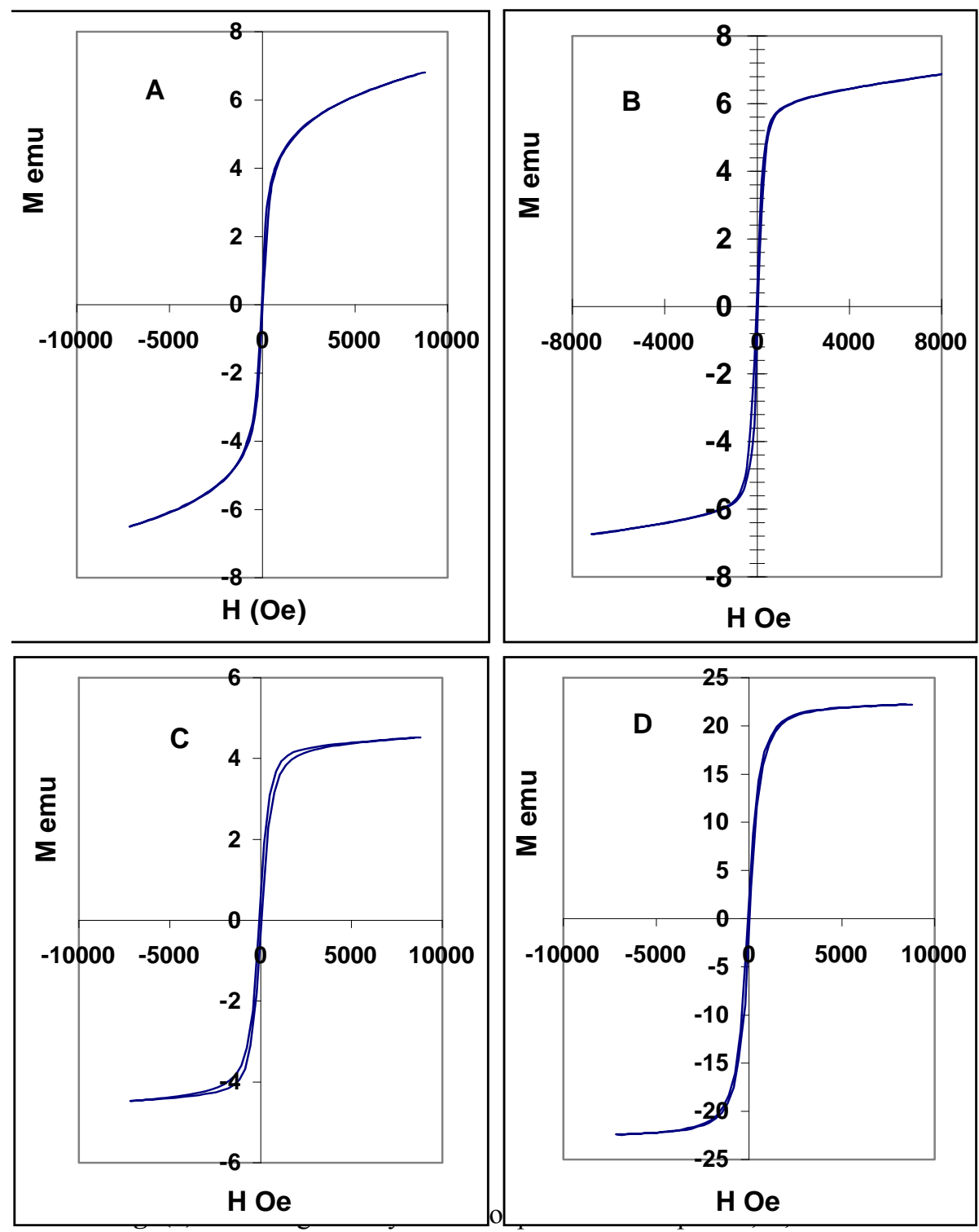

Table (3): The effect of nano crystal size on the magnetic parameters; coercive field $\mathrm{H}_{\mathrm{C}}$, the magnetic field $\mathrm{H}_{\mathrm{Max}}$, at which the saturation 
magnetization occurs, threshold field $H_{t}$, remenance ratio $M_{r} / M_{m}$, effective magnetic moment $\mu_{\text {eff. }}$ and Curie temperature $\mathrm{T}_{\mathrm{C}}$.

\begin{tabular}{||c||c|c|c|c|c|c|c||}
\hline \hline Samples & $\begin{array}{c}\text { Crystal Size } \\
(\mathrm{nm})\end{array}$ & $\begin{array}{c}\mathrm{H}_{\mathrm{C}} \\
(\mathrm{Oe})\end{array}$ & $\begin{array}{c}\mathrm{H}_{\mathrm{Max}} \\
(\mathrm{Oe})\end{array}$ & $\begin{array}{c}\mathrm{H}_{\mathrm{t}} \\
(\mathrm{Oe})\end{array}$ & $\mathrm{M}_{\mathrm{r}} / \mathrm{M}_{\mathrm{m}}$ & $\begin{array}{c}\mu_{\text {eff }} \\
(\mathrm{B} . \mathrm{M})\end{array}$ & $\begin{array}{c}\mathrm{T}_{\mathrm{C}} \\
(\mathrm{K})\end{array}$ \\
\hline \hline $\mathrm{A}$ & 9.6 & 29.87 & 7968 & 1050 & 0.152 & 13.67 & 583 \\
\hline $\mathrm{B}$ & 45.2 & 34.41 & 7970 & 489 & 0.236 & 18.26 & ----- \\
\hline $\mathrm{C}$ & 50.4 & 43.56 & 7974 & 878 & 0.147 & 15.25 & 544 \\
\hline $\mathrm{D}$ & 108.6 & 68.19 & 7985 & 871 & 0.179 & 10.01 & 541 \\
\hline
\end{tabular}

A comparison between the results obtained in Table (3) for samples A, B and $\mathrm{C}$ confirms that heating duration steps decreases the ferromagnetic temperature range of the prepared samples while Ce-doping increases it. This is an economic result. Also, it is noted that the highest reminence ratio is obtained for sample B and the lowest coercive field for sample A. This is due to the stoichiometry of Mn containing spinel ferrites which has a strong effect on the shape of the hysterics loop, where the squareness ratio is larger at higher concentration of anion vacancies [28].

The dependence of magnetic susceptibility on temperature at different magnetic field intensities (6600e-16900e) for sample D as a typical curve is shown in Fig. (5.a), while Fig. (5.b) illustrates a comparison of the susceptibility curve between the four investigated samples at 1010 Oe. The results indicate that sample B has a paramagnetic behavior, while the other samples have ferromagnetic character. The different behavior of sample $\mathrm{B}$ is mainly due to the presence of $\mathrm{Fe}_{2} \mathrm{O}_{3}$ which has a significant effect on the sample magnetization properties. The Curie temperature $\mathrm{T}_{\mathrm{C}}$ of each sample was calculated from the intersection of the curve tangents in the ferromagnetic and paramagnetic regions. The effective magnetic moment has also been calculated from the curves of the reciprocal of magnetic susceptibility against temperature and the results are reported in Table (3).

\subsection{Dielectric behaviours:}

The basic conduction mechanism in ferrites is the thermally activated hopping from one cation to adjacent one. Multivalent cations, such as iron, manganese, cerium etc. play the key role in the conduction process for solid of this kind [1, 21 and 24]. Fig. (6) illustrates the variation of the real part of the dielectric constant $\varepsilon^{\prime}$ with absolute temperature at different frequencies $(200$ $\mathrm{kHz}-3 \mathrm{MHz}$ ) for sample $\mathrm{C}$ as a typical curve. The general trend is the decrease of $\varepsilon$ with increasing the frequency, which is the normal dielectric behavior in ferrites. This means that the dipoles cannot follow the alternation of the electric field. The frequency dependence of ferrites dielectric constant arises from four 
types of polarization (interfacial, dipolar, atomic and electronic). The first two of them are highly frequency dependent, while the other last two are frequency independent. The measured values of the dielectric parameters are reported in Table (4).
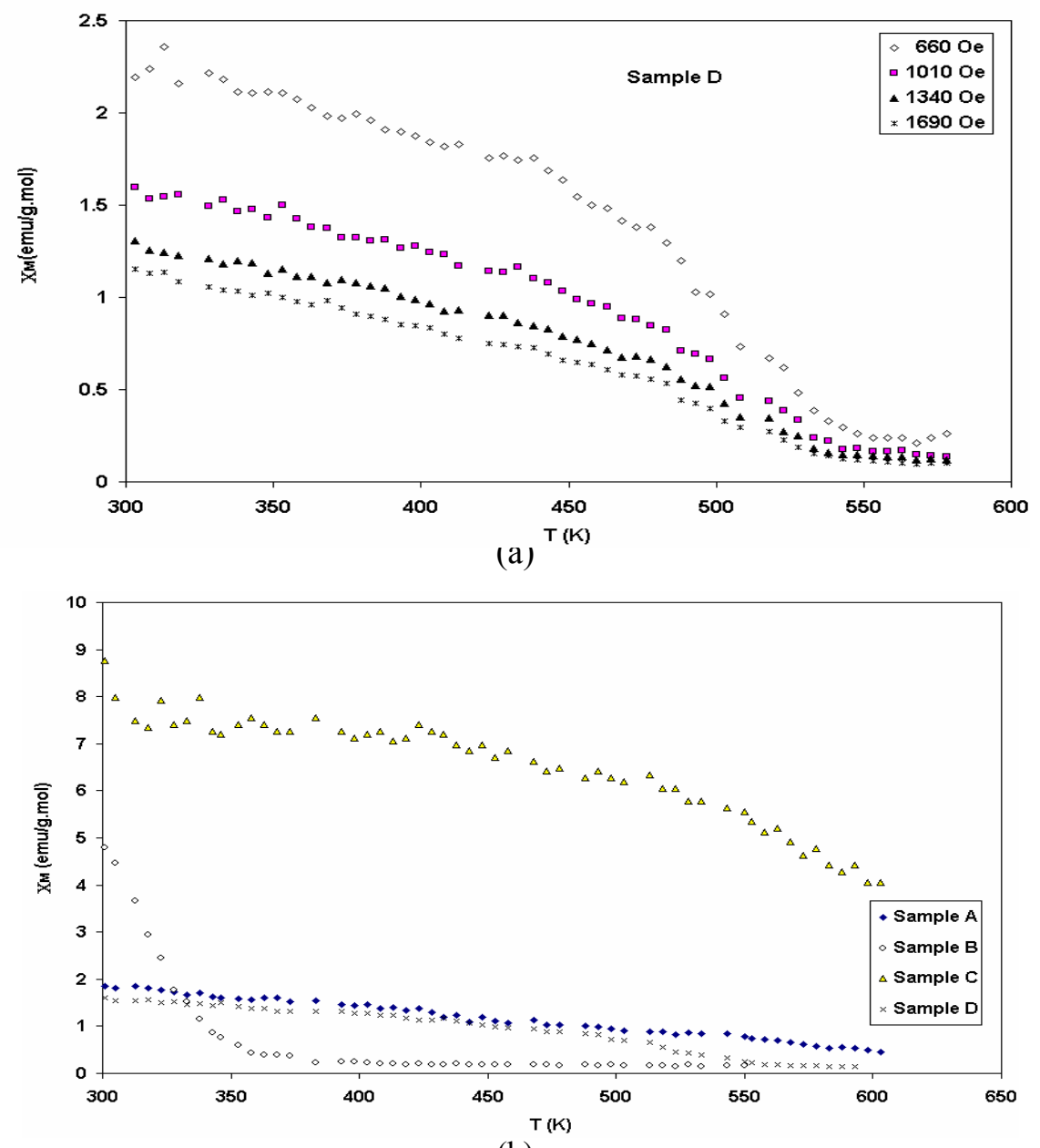

(b)

Fig. (5): The dependence of magnetic susceptibility on temperature at: (a) difference field intensities for the sample D and (b) at 1010Oe for the samples A, B, C and D. 


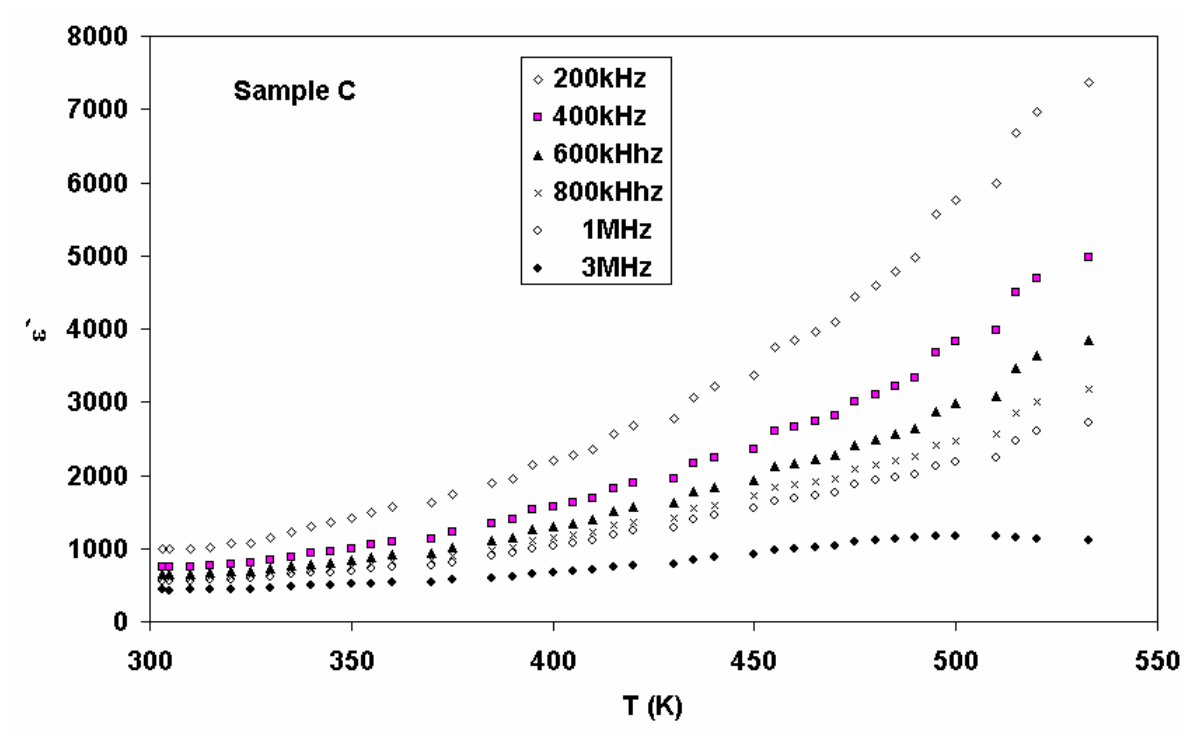

Fig. (6): The variation of the real part of the dielectric constant with

temperature at different frequencies for the sample $\mathrm{C}$

Table (4): The values of dielectric constant $\left(\varepsilon^{\prime}\right)$, the dielectric loss $(\tan \delta)$ the rsistivity $(\rho)$ measured at $(400 \mathrm{~K}$ and $400 \mathrm{kHz})$ and the activation energy $\left(E_{g}\right)$ in the temperature range $(400-600 \mathrm{~K})$.

\begin{tabular}{||c||c|c|c|c||}
\hline Samples & $\varepsilon^{\prime}$ & $\tan \delta$ & $\rho(\Omega \mathrm{cm}) \times 10^{4}$ & $\mathrm{E}_{\mathrm{g}}(\mathrm{eV})$ \\
\hline \hline A & 500 & 1.12 & 1 & 0.81 \\
\hline B & 200 & 0.07 & 25 & 0.98 \\
\hline C & 1500 & 1.01 & 0.3 & 0.38 \\
\hline D & 220 & 0.46 & 4.8 & 0.92 \\
\hline
\end{tabular}

The data show that the highest value of $\varepsilon^{\prime}$ and lowest resistivity are obtained for sample $\mathrm{C}$. The further heat-treatment for this sample increases the occurrence of the exchange interaction $\mathrm{Fe}^{2+} \rightarrow \mathrm{Fe}^{3+}+\mathrm{e}$ and in turn decreases the resitivity. Moreover, it leads to a substantial structural improvement as revealed by TEM studies. Accordingly, sample $\mathrm{C}$ is recommended for electronic applications. Fig. (6) shows also that the dielectric constant increases with temperature at all frequencies. The increase at low frequencies is quite significant as it was discussed above [25]. 
The dielectric loss in ferrites is a measure of lag in the polarization with respect to the alternating field [1]. The variation of the dielectric loss $\tan \delta$ against the temperature at different frequencies is shown in Fig. (7), for sample $\mathrm{C}$ as a typical curve. Both the dielectric constant and dielectric loss increase with temperature for all samples with different particle size. This can be attributed to the increase of the mobility of charge carriers as well as their hopping rate with temperature [12 \& 26]. The behavior of $\tan \delta$ in ferrites is usually reflected in the resistivity measurements. The high-resistivity materials exhibit low dielectric losses and vice versa [27]. However, the results given in Table (4) reveal a reverse trend for sample A $\left(9.9 \mathrm{~nm} \mathrm{Mn}_{0.45} \mathrm{Ce}_{0.1} \mathrm{Fe}_{0.45} \mathrm{O}_{4}\right)$. This can be explained due to the presence of $\mathrm{Ce}$ ions that give rise to hole hopping $\mathrm{Ce}^{3+} \leftrightarrow \mathrm{Ce}^{4+}$, whose hopping rate should be smaller than that of electron hopping. On the other hand, it is noted that, the dielectric loss for sample B is very small in comparison with that of other samples. Thus, it is a suitable candidate for microwave applications.

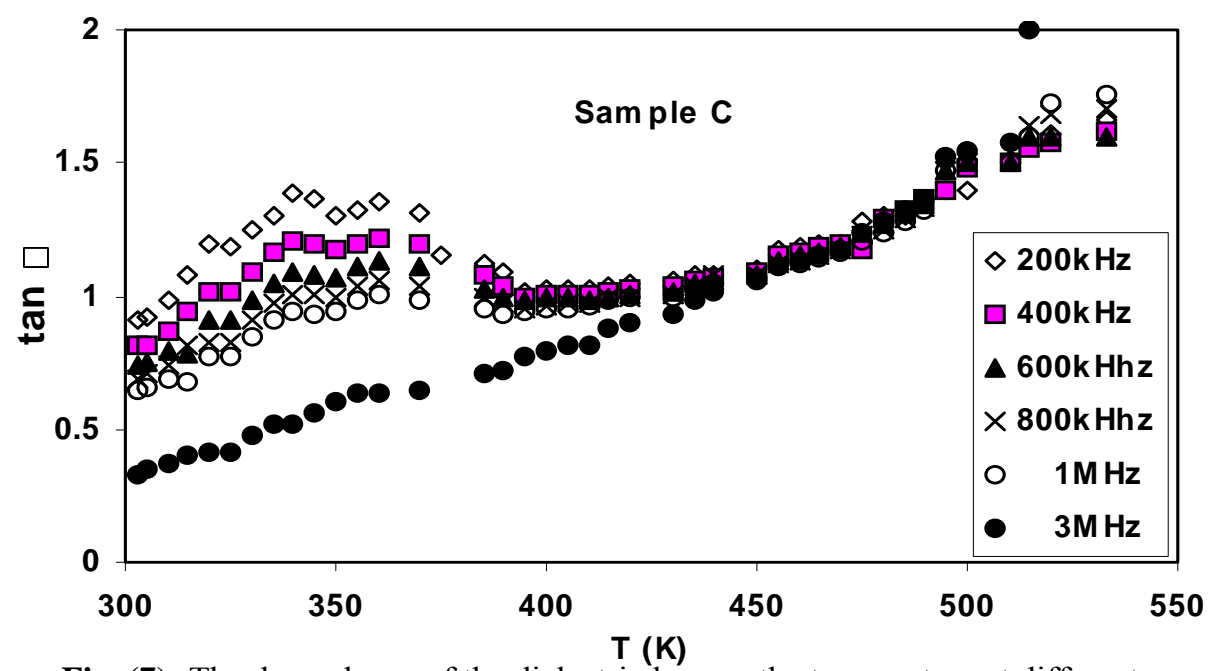

Fig. (7): The dependence of the dielectric loss on the temperature at different frequencies for sample $\mathrm{C}$.

\section{Conclusion:}

The obtained hysteresis loops of all the investigated samples belong to the Isoperm loop. The ferromagnetic nature of this type of ferrite increases with increasing the heat-treatment steps and decreases with Ce-doping. It is of importance to emphasize that sample A has the lowest crystal size, lowest coercive field and highest Curie temperature. It can, thus, be used in medical applications. Sample B reveals a paramagnetic behavior. Its dielectric loss is the 
lowest by an order of magnitude. It can be effectively utilized in storage memory and in microwave applications. Finally, sample $\mathrm{C}$ has the highest dielectric constant and lowest resistivity. It is recommended for electronic applications.

\section{References:}

1. N. SivaKumar, A. Narayanasamy, C. N. Chinnasamy and B. Jeyadevan J. Phys.: Condens. Matter, 19, 386201 (2007).

2. R. W. Siegel Phys. Today, 46, 64 (1993).

3. M. Sugimoto J. Am. Ceram. Soc. 82, 269 (1999).

4. A. S. Lübbe, C. Bergemann, J. Brock and D. G. McClure J. Magn. Magn. Mater. 194, 149 (1999).

5. J. W. M. Bulte, M. de Cuyper, D. Despres and J. A. Frank J. Magn. Magn. Mater. 194, 204 (1999).

6. M. A. Ahmed, N. Okasha and S. I. El-Dek Nanotechnology 19, 065603 (2008).

7. C. Alvani, G. Ennas, A. La Barbera, G. Marongiu, F. Padella and F. Varsano Int. J. Hydrogen Energy 30, 1407 (2005).

8. Z. Bianfang, T. Guide, Y. Zonglin, W. Zhenbiao, Y. Qingfen and C. Jianpo J Wuhan Univ. of Technology-Mater Sci. Ed. 22 (3), 514 (2007).

9. V. Musat Bujoreanu, E. Segal, M Brezeanu, R. Salmon, J. J. Videau and C. Gheorghies Thermochimica acta 288, 221 (1996).

10. E. J. W. Verwey, P. W. Haaijman, F. C. Romeyn and G. M. Van Osterhout Phil. Res. Rep. 5, 173 (1950).

11. M. Goyot J. Magn. Magn. Mater. 18, 925 (1980).

12. N. Ponpandian, P. Balaya and A. Narayanasamy J. Phys.: Condens. Matter. 14, 3221 (2002).

13. B. Gillot and P. Tailhades J. Magn. Magn. Mater. 208, 181 (2000).

14. J. Wang, H. Deng, Y. Li, P. Song and J. Shi J. Magn. Magn. Mater. 320, 227 (2008).

15. $\mathrm{S} \mathrm{Ke}, \mathrm{L}$ Zhongwen, $\mathrm{C}$ Shengming, $\mathrm{S}$ Yueming and $\mathrm{Y}$ Zhong Rare Metals 25, 509 (2006).

16. M. A. Ahmed and Samiha T. Bishay J. Phys. D: Appl. Phys. 34, 1339 (2001).

17. Samiha T. Bishay J. Magn. Magn. Mater. 301, 231 (2006).

18. T. Valdés-Solis, P. Valle-Vigon, S. Álvarez, G. Marbán and A. B. Fuertes, Catalyst Communications 8, 2037 (2007).

19. Y. Li, J. Jiang and J. Zhao Material Chem. Phys. 87, 91 (2004).

20. J. Pattanayak J. Mater. Sci. Lett. 9, 13 (1990).

21. R. Hochschild and H. Fuess J. Mater. Chem. 10, 539 (2000). 
22. Dr-Ing. Carl Heck, "Magnetic Material and their Applications" London Butterworth \& Co. (Publishers) LTD, (1974).

23. T. P. Raming, A. J. A. Winnubst, C. M. van Kats and A. P. Philipse, J. Colloid Interface Sci. 249, 346 (2002).

24. J T S Irvine, A. Huanosta, R. Velenzuela and A. R. West, J. Am. Ceram. Soc. 73, 729 (1990).

25. A. Verna, O. P. Thakur, C. Prakash, T. C. Goel and R. G. Mendiratta, Mater. Sci. Eng. B, 1161 (2005).

26. M. A. Hiti, J. Magn. Magn. Mater. 164, 231 (1968).

27. G. Ranga Mohan, D. Ravender, A. V. Ramana Reddy and B. S. Boyanov, Mater. Lett. 40, 39 (1999).

28. M. A. Zinovik and E. V. Zinovik, Inorganic Materials, 40 (5), 533 (2004). 